\title{
The interurban DRAG-Spain model: The main factors of influence on road accidents in Spain
}

\author{
Francisco Aparicio Izquierdo Blanca Arenas Ramírez $\quad$ Eva Bernardos Rodríguez
}

\begin{abstract}
A B S T R A C T
This paper presents the results of applying DRAG methodology to the identification of the main factors of influence on the number of injury and fatal accidents occurring on Spain's interurban network. Nineteen independent variables have been included in the model grouped together under ten categories: exposure, infrastructure, weather, drivers, economic variables, vehicle stock, surveillance, speed and legislative measures. Highly interesting conclusions can be reached from the results on the basis of the different effects of a single variable on each of the accident types according to severity. The greatest influence revealed by the results is exposure, which together with inexperienced drivers, speed and an ageing vehicle stock, have a negative effect, while the increased surveillance on roads, the improvement in the technological features of vehicles and the proportion of high capacity networks have a positive effect, since the results obtained show a significant drop in accidents.
\end{abstract}

\section{Introduction}

Traffic accidents are a major problem in developed societies and are the primary cause of death among the young population. In 2006, in Spain, there were 99,797 accidents with victims; 4104 fatalities and 21,382 seriously injured on interurban roads.

The important objective of reducing accidents and victims adopted by the European Commission and most EU countries, including Spain, requires Strategic Plans to be drawn up containing numerical objectives and the adoption of policies and road safety measures capable of achieving these objectives. Given the large number of factors influencing the rate of accidents and victims, how they are interrelated and their evolution over time, predicting the effects of these policies and measures is impossible without the application of scientific analytical methods and an evaluation of the variables of influence inside a framework of specific scenarios that are representative of the actual situation that is being taken into account at a national or regional level.
Applying multivariate models is a very useful recourse as the effect of each of the variables of influence can be dealt with. Apart from evaluating the expected contribution of the main variables of influence, or the lines of action taken, there is great interest in developing models that combine the ability to take account of a wide range of factors on a macroscopic level, as well as being able to make predictions by considering different scenarios.

The University Institute for Automobile Research (INSIA), part of Madrid Technical University, has developed a model based on DRAG methodology, called the I-DE model. The model consists of four explanatory layers to cover exposure, accidents, severity and victims in Spain's interurban road network. This paper sets out the results of the accident models concerning the explanation of injured and killed victims.

The paper is structured as follows. Firstly, it presents a review of the main works in the sphere of macroscopic accident models, with special attention on international developments and DRAG model applications. Then the main features of the DRAG statistical methodology are set out, as well as their main advantages compared to other similar models. This is followed by the approach to the model, the sources of information and the main results in terms of the elasticity of each of the variables included in the model comparing them with the findings of other authors. The paper concludes with a discussion of the main conclusions. 


\section{State-of-the-art}

There is a wide range of techniques and methodologies that enable the factors of influence on road safety to be approached. In general, the choice of methodology depends on the goals pursued, the variables of interest and the availability of information. The socalled microscopic models can be taken to make an initial classification, where the unit of observation is usually an accident or a series of accidents that occur on short segments of road, while the macroscopic models can be taken where analysis is focused on studying the evolution over time of the number of accidents and victims in a particular geographic area.

The macroscopic models apply different methodologies depending on the objectives of the study. Prediction-based studies will use models where only time appears as an exogenous factor and no explanatory variable is taken into account. When the ultimate objective is to describe a process, the explanatory models are usually a better option since they include independent variables that help explain the phenomenon under analysis. This type of model was widely used in the decade of the 80s with structures similar to those of an exponential model, with variables like exposure, average income, alcohol consumption or the percentage of young people in the population, and even intervention variables.

Important contributions in the area of macroscopic models were made by Robertson (1981), Jocksch (1984), Graham and Garber (1984), Partyka (1984, 1991) and Zlatoper (1984, 1987, 1989, 1991). Later, Hakim, Shefy, Hakkert, and Hocherman (1991) and Lassarre (1994) undertook an in-depth review of the methodologies used and the results obtained concerning the main risk factors. These initial experiences were mostly based on simple regression models applied to annual series of accidents or victims. The most common drawbacks with this type of model, such as multicollinearity and/or autocorrelation of the residuals, as well as the imposition of the functional relationship between the variables, conditioned the building of the model and its subsequent application.

These problems were approached and solved to a large extent in 1984 with the development of the DRAG method (Demande Routière, Accidents et Gravité). This method, based on a recursive structure with three layers of analysis was first used by Gaudry (1984) for the province of Quebec under the name DRAG-1 and was subsequently improved and again applied as DRAG-2 to the region by Fournier and Simard (1999). The ensuing results then led to its being applied in other countries and regions, as it is described in Gaudry and Lassarre (2000): Germany (SNUS; Blum \& Gaudry, 1999, Norway (Truls-1; Fridstrøm, 1997), Stockholm (DRAG-Stockholm-2; Tegnér, 1998), France (TAG-1; Jaeger, 1998), California (TRACS-CA; McCarthy, 1999) and Belgium (Van den Bossche \& Wets, 2003) adapted this methodology to their own circumstances.

DRAG-type models were given special mention in OECD (1997) and COST 329 (1999) reports. After the DRAG models were developed, reviews in this field continued to be carried out (Lassarre, 2000; Page, 2001), although, in general, with different goals from those pursued in this work.

\section{DRAG methodology}

When the ultimate goal is to conduct an in-depth analysis of the causal factors behind accident rates, it is preferable to study the phenomenon in a more disaggregated way and analyse the main components.

One of the main characteristics of DRAG models is the development of a multi-layer structure integrating the three main road safety dimensions, (exposure, accident frequency and severity), each of which is the object of its own equation that takes account of the major factors of influence: socioeconomic variables, demographic variables, vehicle stock and its characteristics, infrastructure, drivers, weather and safety legislation, among others.

Therefore, the multi-layer structure is defined by the following equations:

$$
\left[\begin{array}{l}
\text { Exposure } \leftarrow\left[-----, \text { Other factors }\left(\mathrm{X}_{1}\right)\right] \\
\text { Accidents } \leftarrow\left[\mathrm{DR}, \text { Other factors }\left(\mathrm{X}_{2}\right)\right] \\
\text { Severity } \leftarrow\left[\mathrm{DR} \text {, Other factors }\left(\mathrm{X}_{3}\right)\right]
\end{array}\right],
$$

where $D R$ is exposure and $X_{i}$ are the explanatory factors in each dimension whose relation to the variable to be modelled or dependent variable will be established using statistical fitting, thereby providing an optimal measurement for analysing the influences. In addition, exposure is introduced as an independent variable within the accident and severity equations, so it is the model itself that determines the relation between both variables without any need to impose a fixed proportionality relationship that is inherent to many of the previous models.

By analysing each of the dimensions of road safety and combining their outcomes, the number of victims can be obtained from the following equation:

Victims $=$ accidents $\times$ severity

The statistical model used for DRAG models consists of three equations from which the functional form of the model is established using the Box-Cox transformation (3), the heteroscedasticity is corrected (4) as well as the autocorrelation (5):

$$
\begin{aligned}
& Y_{t}^{\left(\lambda_{y}\right)}=\sum_{k=1}^{K} \beta_{k} X_{k t}^{\left(\lambda_{x k}\right)}+u_{t} \\
& u_{t}=v_{t} * f\left(Z_{m t}\right)^{1 / 2} \\
& v_{t}=\sum_{l=1}^{r} \rho_{l} * v_{t-l}+w_{t}
\end{aligned}
$$

where: $Y_{t}$ is the variable dependent for month $t$; $\lambda_{y}$ is the transformation parameter associated with the dependent variable $Y_{t} ; X_{k t}$ represent the exogenous $k$ variables for month $\mathrm{t} ; \beta_{k}$ is the regression coefficient associated with the variable $X_{k} ; \lambda_{x k}$ is the transformation parameter associated with the independent variable $X_{k} ; u_{t}$ is the error term without correction of autocorrelation and heteroscedasticity; $v_{t}$ is the homoscedastic error term without correction of autocorrelation; $Z_{m t}$ represent the heteroscedasticity variables; $\rho_{l}$ are the autorregresive parameters associated with delay $l ; w_{t}$ is white noise with constant variance.

In the first equation the variables to be modelled, $Y_{t}$ and the factors of influence, $X_{k \mathrm{t}}$, are subjected to the Box-Cox transformation (BCT); therefore the model takes on a flexible functional form with the data themselves determining the relation between the variables. The Box-Cox transformation is defined for any positive variable as follows:

$$
Y_{t}^{\left(\lambda_{y}\right)}=\left\{\begin{array}{cl}
\frac{Y_{t}^{\lambda_{y}}-1}{\lambda_{y}} & \lambda_{y} \neq 0 \\
\ln \left(Y_{t}\right) & \lambda_{y}=0
\end{array}\right.
$$

Heteroscedasticity in the residuals $u_{t}$. is corrected using the Eq. (4). The variables $Z_{t}$ are the heteroscedasticity factors, and are inserted into the model according to the inverse of the Box-Cox transformation, with the transformation parameter equalled to zero, as follows: 


$$
\left.\left.f\left(Z_{m t}\right)=I B C T \sum_{m=1}^{M} \delta_{m} Z_{m t}\right)=\exp \sum_{m=1}^{M} \delta_{m} Z_{m t}^{\left(\lambda_{m}\right)}\right)
$$

and the quotient between both terms generates a new residual $v_{t}$, of constant variance.

Finally, Eq. (5) corrects the autocorrelation of the residuals $v_{t}$ assuming they follow a autoregressive stationary process of order $l$ $(\operatorname{AR}(l))$, so that the error term $w_{t}$ follows a process of white noise.

The TRIO program developed by Liem, Gaudry, Dagenais, and Blum (2000) provides maximum likelihood estimates of all parameters as well as, among other results, the elasticity values and their associated $\mathrm{t}$ statistic, by means of which, the influence and significance of each variable can be analysed. The TRIO program also facilitates the Besley test, whereby the presence of multicollinearity in each model can be analysed. The models have been fitted by paying special attention to this problem, the predicted coefficients being robust both as to value and sign.

\section{Approach to the model, variables and information sources}

When developing a structural model with DRAG model features, it is essential to fit the model structure correctly to the specific conditions of the available data by choosing a suitable space-time framework. In the I-DE model, this adaptation was carried out taking the interurban road network as a mobility framework. This decision was essentially based on two reasons:

- Over $80 \%$ of fatal accidents occur in an interurban environment.

- The availability of more and better data concerning the variables of influence.

The data used to develop the models are monthly series, dating from January 1990 to December 2004, with a total of 180 observations for each variable. The choice of this timeframe was based, on the one hand, on the availability of data on variables, as many of the variables for study were not recorded prior to 1990, and on the other on prediction, leaving a 2 or 3 year margin for subsequently comparing the data fitted by the models with the actual data.

The dependent variables are the number of accidents with injured and the number of fatal accidents happening on interurban roads, while the independent variables have been grouped under ten categories: exposure, infrastructure, weather, drivers, economic variables, vehicle stock characteristics, surveillance, speed and legislative measures. The data were obtained from different official sources, such as the Government's General Traffic Directorate (accident data, vehicle stock, drivers, surveillance, infractions and legislative measures), the Ministry of Public Works (data on exposure and infrastructure), the National Meteorological Office (weather data) and the National Statistics Office (economic data).

\section{Obtaining and selecting variables; disaggregation procedures}

Since dependent and independent variables are highly important in DRAG methodology, a large part of the effort put into this work has been devoted to selecting them and obtaining and processing the available data.

Firstly, a meticulous study was undertaken of the variables included in the DRAG models produced up to present. Analysing these results enabled a series of priorities to be established when compiling the variables to be analysed in the DRAG-Spain model, based fundamentally on the influence and significance obtained from these models. Obtaining the prioritised variables data to develop the models was not exempt from problems, since many of the variables of interest were not even available in data bases, while the ones that were did not fit in with the monthly frequency required by the model.

The lack of data meant that variables as important as speed, the use of seat-belts and crash-helmets or the number of vehicles failing their technical test had to be ignored. The number of variables recorded per month as opposed to other time frequencies, was a determining factor in the use of supplementary procedures to obtain the required frequency, and in some cases meant searching for supplementary variables or a proxy of those required.

Table 1 shows the final variables, their frequency of recording and when no monthly records were available, the calculation method used to obtain the variable as a monthly frequency. Therefore, four well-differentiated groups can be established for obtaining this:

1. Direct: all variables recorded on a monthly basis and therefore obtained directly from official sources are considered as direct.

2. By interpolation: by using interpolation, data for the variable on a monthly basis was obtained without using any other variable. This is the case with the variables concerning the percentage of high capacity network, driver census and the percentage of vehicle stock equipped with $A B S$, whose primary data are on an annual basis. The nature of this type of variable, with no or little seasonality, means it is possible to apply a reasonable rate of change by month without the fear of there being unrecorded fluctuations.

3. By disaggregation: the disaggregation of variables is a supplementary process that allows obtaining a high frequency series

Table 1

Explanatory factors.

\begin{tabular}{|c|c|c|}
\hline Explanatory factors & Obtained by & $\begin{array}{l}\text { Recording } \\
\text { frequency }\end{array}$ \\
\hline \multicolumn{3}{|l|}{ Exposure } \\
\hline Kilometres travelled by light vehicles & Extrapolation & Annual \\
\hline $\begin{array}{l}\text { Kilometres travelled by heavy vehicles } \\
\text { Infrastructure }\end{array}$ & and disaggregation & Annual \\
\hline $\begin{array}{l}\text { Expenditure on intercity network } \\
\text { maintenance }\end{array}$ & Interpolation & Annual \\
\hline $\begin{array}{l}\text { Percent high capacity intercity roads } \\
\text { Weather }\end{array}$ & Interpolation & Annual \\
\hline Days with temperature below $0^{\circ} \mathrm{C}$ & Direct & Monthly \\
\hline Mean precipitation & Direct & Monthly \\
\hline Hours of sunlight & Direct & Monthly \\
\hline Average temperature & Direct & Monthly \\
\hline Foggy days & Direct & Monthly \\
\hline Days with snow & Direct & Monthly \\
\hline $\begin{array}{l}\text { Days with snow-covered ground } \\
\text { Drivers }\end{array}$ & Direct & Monthly \\
\hline $\begin{array}{l}\text { Percent drivers less than } 1 \text { year's experience } \\
\text { Economic conditions }\end{array}$ & Direct & Monthly \\
\hline $\begin{array}{l}\text { Number of unemployed } \\
\text { Calendar }\end{array}$ & Direct & Monthly \\
\hline Working days & Direct & Monthly \\
\hline $\begin{array}{l}\text { Saturdays, Sundays and public holidays } \\
\text { Vehicle stock characteristics }\end{array}$ & Direct & Monthly \\
\hline Average age of vehicle stock & Interpolation & Annual \\
\hline Percentage of vehicle stock over ten years old & Interpolation & Annual \\
\hline Percentage of private cars with ABS & Interpolation & Annual \\
\hline Percentage of private cars with ESP & Interpolation & Annual \\
\hline Surveillance & & \\
\hline Number of random breath tests & Direct & Monthly \\
\hline Number of random breath test positive & Direct & Monthly \\
\hline Number of officers in Civil Guard Traffic Dep & Direct & Monthly \\
\hline $\begin{array}{l}\text { Number of driving licences suspended } \\
\text { Speed }\end{array}$ & Direct & Monthly \\
\hline Number of radar checks & Direct & Monthly \\
\hline $\begin{array}{l}\text { Percent drivers with positive in radar checks } \\
\text { Safety laws }\end{array}$ & Direct & Monthly \\
\hline 1992 Traffic Act & Direct & Monthly \\
\hline Reduction of alcohol limits in 1999 & Direct & Monthly \\
\hline
\end{tabular}


(monthly, in this case), from a low frequency series (annual or quarterly), by using a supplementary variable called an indicator, whose monthly behaviour is known and very closely related to the required variable.

4. By extrapolation and disaggregation: there are variables that were not recorded during the entire study period (1990-2004), which meant extrapolating the annual figures for those where no information was available, so that the most appropriate disaggregation procedure could then be applied. This was the case for exposure, whose monthly variation was obtained from the exposure data related to toll motorways of the State Road Network (RCE).

Finally, when it was impossible to obtain the required figure, it was decided to include other variables in the model that best represented the phenomenon that it was wished to explain, such as the relationship between speed and accidents. Mean monthly speed figures have been available from 2004 onwards, but unfortunately these data are not sufficient to complete the series throughout the whole study period. It was finally decided to include radar checks and the number of cases of excess speed reported. These were available monthly but in the end only the second variable was included in the models.

If a lack of data on variables is a determining factor when it comes to developing models, multicollinearity is the main problem when it comes to estimating the elasticities associated with these variables, since in the face of high correlations between variables, the predicted elasticities can turn out to be imprecise. Therefore, the results need to be correctly obtained and interpreted for the predicted elasticities in the model to be robust from a statistical point of view, lacking in bias and with no fluctuations of sign or value conditioned to other variables in the model. For this reason, the models finally presented here do not include all the variables selected initially, and the ones finally presented are the result of an exhaustive analysis of the outcomes of the model generated based on applying priority criteria that can be summarised as:

a. The degree of interest for the study according to the research team's criteria.

b. The expected degree of influence of the variable.

c. The greatest possibility of the authorities being able to take action.

d. The least correlation with the other variables of the model.

Due to problems of multicollinearity the variables eliminated from the models were:

- Hours of sunlight: the variables of hours of sunlight and temperature show a correlation coefficient of 0.85 . Since both variables are considered of high interest, the final choice for the temperature variable was based on statistical significance and the greatest correlation of the hours of sunlight variable with other variables in the models.

- Days with a temperature equal to or lower than $0^{\circ} \mathrm{C}$ : this variable was eliminated from the models due to the correlation existing with other weather variables, particularly with temperature.

- Days of snow: given the availability of two snow-related variables in the data base, it was decided to include in the model the one that gave the fewest problems of multicollinearity.

- Working days: the presence of two variables related to the different types of days (weekends, public holidays and working days), generated strong correlations with one another. Finally, it was decided to include the variable of Saturdays, Sundays and public holidays to analyse their effect on the higher incidence of accidents on these days.
- Vehicle stock average age: the variables of vehicle stock average age and the percentage of vehicles over 10 years old are highly correlated, which means that one of them had to be eliminated. The inclusion of the average age variable, moreover, caused alterations to the value and even to the sign of the elasticities associated with the percentage of learner drivers and the percentage of length of high capacity occupation, so the second was decided on.

- Percentage of vehicle stock fitted with ESP: the problems of this variable were mainly linked to the variable of the percentage of vehicles fitted with ABS. Both follow a similar tendency which causes the model not to differentiate the effects associated with one or other variable and predicts a sign contrary to what was expected for one of the two variables when they are inserted together into the models. The longer time period for ABS to be brought into service was the determining factor for choosing this variable compared to ESP.

- Percentage of positives in breath tests: initially, it was attempted to analyse the two available alcohol-related variables (random breath tests and percentage of positives in controls), but the existing correlation, not only between these two, but with other surveillance variables, forced the elimination of the positives variable with the random breath test variable being finally included, which, in addition, showed fewer problems of multicollinearity.

- Radar checks: what is explained for alcohol variables is perfectly comparable to the speed variables (Radar checks and positives in controls), only in this case the variable eliminated from the model was that related to radar checks.

\section{Results}

Nineteen variables were identified that largely explain the monthly variations in the number of accidents with injured and fatalities. Table 2 sets out the results of the elasticities associated

Table 2

Accident models.

\begin{tabular}{|c|c|c|}
\hline Explanatory factors & $\begin{array}{l}\text { Accidents } \\
\text { with injured }\end{array}$ & Fatal accidents \\
\hline \multicolumn{3}{|l|}{ Exposure } \\
\hline Vehicle kilometres & $+7.16(6.49)$ & $+7.66(4.9)$ \\
\hline Proportion of heavy vehicles & $-2.77(-2.69)$ & $-0.38(-0.27)$ \\
\hline \multicolumn{3}{|l|}{ Infrastructure } \\
\hline Investment in maintenance & $-1.94(-1.29)$ & $+2.23(1.39)$ \\
\hline $\begin{array}{l}\text { Proportion of high capacity Network length } \\
\text { Weather }\end{array}$ & $-2.34(-0.95)$ & $-2.87(-0.63)$ \\
\hline Foggy days & $+0.09(0.86)$ & $+0.04(0.19)$ \\
\hline Days with snow-covered ground & $+0.15(1.75)$ & $-0.05(-0.21)$ \\
\hline Mean precipitation & $+0.15(1.78)$ & $-0.39(-2.94)$ \\
\hline Temperature & $+0.42(1.19)$ & $+0.18(0.21)$ \\
\hline \multicolumn{3}{|l|}{ Drivers } \\
\hline Percentage of learner drivers & $+0.4(0.2)$ & $+4.17(2.51)$ \\
\hline \multicolumn{3}{|l|}{ Economic conditions } \\
\hline $\begin{array}{l}\text { Registered unemployed } \\
\text { Calendar }\end{array}$ & $-1.97(-2.07)$ & $-1.07(-0.6)$ \\
\hline \multicolumn{3}{|l|}{ Vehicle stock characteristics } \\
\hline Percentage of vehicles over 10 years old & $8.71(-0.13)$ & $9.05(-2.95)$ \\
\hline Percentage of vehicles with ABS & $-0.12(-0.40)$ & $-0.65(-2.32)$ \\
\hline \multicolumn{3}{|l|}{ Surveillance } \\
\hline Random alcohol checks & $-0.04(-0.13)$ & $-1.38(-2.95)$ \\
\hline Traffic officers & $-2.09(-0.86)$ & $-3.59(-1.69)$ \\
\hline $\begin{array}{l}\text { Driving licence suspensions } \\
\text { Speed }\end{array}$ & $-0.27(-0.79)$ & $-0.69(-1.45)$ \\
\hline $\begin{array}{l}\text { Percentage of positives in radar checks } \\
\text { Acts }\end{array}$ & $0.9(0.98)$ & $0.96(0.74)$ \\
\hline Act to reduce the limits of blood alcohol & $0.8(0.13)$ & $-4.4(-1.38)$ \\
\hline 92 Act & $-14(-3.45)$ & $-12.3(-1.74)$ \\
\hline
\end{tabular}


with each variable as well as the value of its $t$-statistic within brackets, which determines the degree of significance of the variable. The results were analysed by groups of variables, giving their value in terms of elasticity related to an increase of $10 \%$, that is, the expected increase in the number of accidents if there is an increase of $10 \%$ in each independent variable, the other factors remaining constant.

\subsection{Exposure}

Exposure is probably the variable that most influences accident frequency. The most suitable unit of measurement to analyse this are the vehicle-kilometres travelled, but some studies, usually through lack of reliable information, have used other indirect measurements such as vehicle stock or population.

In many previous works it was usual practice to assume a proportional relationship between accidents and the exposure measurement chosen, by modelling the variable in the form of a ratio (accidents per kilometre travelled). The hypothesis of a proportional relationship between accident frequency and exposure has been rejected by various studies, (Bonneson \& McCoy, 1993; Fridstrøm \& Ingebrigtsen, 1991; Fridstrøm, Ifver, Ingebrigtsen, Kulmala \& Thomsen, 1995; Kulmala, 1995; Mountain, Fawaz, \& Jarret, 1996) who obtained elasticity values for exposure that were lower than for the unit when this measurement was inserted as one more independent variable into the model.

\subsubsection{Total exposure}

Measured by the number of vehicle-kilometres travelled by all the vehicle stock in the interurban network. According to the model results, accidents are not proportional to exposure. Thus, a $10 \%$ increase in exposure means a $7.16 \%$ increase in accidents with injured and a $7.66 \%$ increase in accidents with fatalities. These results agree with those given by other models as has already been pointed out.

\subsubsection{Proportion of heavy vehicles}

Measured in terms of the vehicle-kilometres run by heavy vehicles in the interurban road network. The influence of this variable differs both in value and significance between accident types. While accidents with injured drop by $2.77 \%$, fatal accidents scarcely drop by $0.38 \%$. The results of parallel analyses carried out by the research group, using other methodology, have shown that these results could be strongly influenced by the drop in the percentage of kilometres travelled by heavy vehicles during the summer months, when there is a high increase in the number of private cars. The elasticity obtained by the models would seem to capture this phenomenon since part of the increased risk in July and August is attributable to the drop in heavy vehicles. For this reason, these elasticities could be overestimated and should be interpreted with caution until more detailed analyses become available.

\subsection{Infrastructure}

The influence of infrastructure has been examined through two variables; in first place, through the percentage of high capacity roads. The data available show that the risk of accident on motorways and dual carriageways (dual carriageways in Spain are similar to motorways, with more demanding construction features in some sections), is much lower than on conventional roads. In Spain, according to figures published in 2004 by the Ministry of Public Works, the number of accidents with victims per thousand million vehicle-kilometres was 96 on toll roads, 112 on free motorways and 246 on conventional roads. Data available in other countries lead to similar conclusions. Therefore, the proportion of high capacity road (motorways and dual carriageways) should play an important role as a variable in the model.

The second aspect taken into account is expenditure on infrastructure maintenance. Most significant of the most widely analysed variables of previous studies are winter road maintenance and road surface improvements. Although the results are unanimous in the first case with their prediction of an important drop in accidents (Sävenhed, 1994), in the second case the estimated coefficients vary both in value and sign, predicting drops in accidents associated with improvements in surface adherence (Tromp, 1994; Wong, 1990), but increases in the event of improvements in uniformity or resurfacing (Hauer, Terry, \& Griffith, 1994; Start, Kim, \& Berg, 1996 In: Elvik \& Vaa, 2004). The higher speed associated with a better perception of the state of the road is probably the main cause associated with these results. In this work, the effects of improvements to road conditions have been included through investment in maintenance.

\subsubsection{Investment in maintenance}

Measured in $€$ per $\mathrm{km}$ of network. Expenditure on maintenance is only available on an annual basis, for which reason it has been necessary to adopt the hypothesis to an equal share over the twelve months of each year. In this case, the elasticities associated differ in sign, being negative for accidents with injured and positive for fatal accidents. Thus, network maintenance would reduce accidents with people injured by $1.94 \%$ while fatal accidents would increase by $2.23 \%$. Although it cannot be ruled out that these results reflect real changes in driver behaviour, these coefficients should be examined with caution. On the one hand, the time when expenditure occurs, in accord with the monthly distribution made, may not coincide with the moment the maintenance operations are carried out. On the other hand, any possible impact in the months following the expenditure have not been taken into account; that is only the effect of the investment in a particular month on the accidents occurring that month has been taken into account, when in reality, it would be expected that the effect of any maintenance would only become manifest in a longer period of time. Finally, an increase in risk in certain sections cannot be ruled out during maintenance work.

\subsubsection{Percentage of high capacity network length}

Measured as the quotient between the length of the high occupation network and the total length of the interurban road network. The models show how increasing the number of kilometres of this type of network favours safety with a reduction of $2.34 \%$ in accidents with injured and $2.87 \%$ for fatal accidents. These results are coherent with the results already commented on.

\subsection{Weather}

It is difficult to analyse the expected effect of adverse weather conditions from studies carried out in other countries due to the fact that differences in the typical weather conditions of each country cause one to suppose that drivers are not going to react equally when faced with changes in factors such as temperature, rain, snow or fog. In general, studies conducted up to present show the negative impact of rain and snow on accidents with victims (Andreescu \& Frost, 1998; Eisenberg, 2004; Fridstrøm et.al 1995). However, there are differences in the results published for fatal accidents: both positive and negative signs can be found for the frequency of fatal accidents. Thus some studies suggest that worsening weather conditions could produce an increase in accidents with victims, and a drop in fatal accidents due to a decrease in the average severity of accidents (Eisenberg, 2004) which might be interpreted as drivers adapting their way of driving to the weather conditions by reducing speed and so avoiding a fatal 
accident, but this is not so with less severe accidents. This coincides with some of the results of the DRAG-Spain model, as will be explained below.

\subsubsection{Foggy days}

Measured as the monthly average number of days with fog. Judging by the model results, fog would not appear to be a factor influencing accidents in Spain, although in both cases the sign obtained is positive. The elasticity values obtained, $0.09 \%$ and $0.04 \%$ for accidents with injured and fatal accidents, are not statistically significant.

\subsubsection{Days with snow-covered ground}

This continuous variable is a quasi-dummy (includes some zeroes) which is why the model presents two outcomes. The first is associated with whether or not there is a day of the month when the ground is covered in snow (dummy): in this instance, the results associate an increase of $1.8 \%$ in the number of accidents with injured victims, and $0.3 \%$ for the number of fatal accidents for those months when the variable takes on a non-zero value. The other elasticity obtained by the model refers to the variation in accidents with the number of days of snow-covered ground: in this instance, the effects on accidents with injured victims differ in sign, since the first indicates an increase by $0.15 \%$ and the second a decrease by $0.05 \%$. This result may have a similar explanation to that already mentioned. It is obvious that a reduction in adherence between the tyre and the road surface results in an objective reduction of safety conditions. However, if drivers adapt their behaviour to road surface conditions by reducing speed, the severity of collisions can also be reduced.

\subsubsection{Precipitation}

Measured as the monthly average precipitation (mm). The results produced are similar to those for the previous variable, although in this case the reduction in accidents is much higher and significant. Thus accidents with injured victims would rise by $0.15 \%$, while fatal accidents would drop by $0.39 \%$. The reasons may be similar to those set out for snow.

\subsubsection{Temperature}

Measured as the average monthly temperature in degrees centigrade. According to the results, a $10 \%$ increase in average temperature leads to a $0.42 \%$ rise in accidents with injured victims and a $0.18 \%$ rise in fatal accidents (not significant).

\subsection{Drivers}

Among the factors associated with drivers, inexperience and age should be underlined as the major causes of increased accident risk. When the model was initially explored, variables associated with both factors were introduced, but the high correlation existing between them required that only one be included. The decision to choose the inexperience-related variable was based on the bibliography consulted, Clarke, Ward, Bartle, and Truman (2006), Gregersen and Bjurulf (1996) and Copper, Pinili \& Chen (1995), which clearly shows the major influence of this age variable on accidents. The characteristics associated with individual behaviour are the main argument behind such results, as demonstrated by Boyce and Geller (2002). In his study Boyce analysed the differences between the way of driving depending on age, highlighting the higher average speed and shorter safety distance when the drivers are young.

\subsubsection{Proportion of learner drivers}

Measured as the percentage of drivers with less than one year's experience. The results reveal a strong rise in fatal accidents as the number of learner drivers increases. The elasticity discovered by the model is higher than $4 \%$. To the contrary, the elasticity associated with accidents with injured victims is barely $0.4 \%$. These results may be explained by younger drivers being more inclined to take risks, whether perceived or not, and these are the majority of learner drivers in a country like Spain.

\subsection{Economic factors}

Many of the studies published analyse the influence of economic factors on traffic accidents with variables such as the Gross Domestic Product (GDP), the level of unemployment or the Industrial Output Index (Joksch, 1984; Scuffham, 1998; Wagennar, 1984). The results show a direct relation between accidents and the economic standing of a country, with accidents falling in times of recession and rising in periods of economic prosperity. To analyse this effect, two points of view have to be taken into account: on the one hand, there is a direct effect through exposure: better economic circumstances are linked to an increase in exposure, and thus more accidents. On the other hand, it has been demonstrated that for a determined amount of exposure, the number of accidents significantly depends on the economic level. The possible explanations for this phenomenon are various. Firstly, some authors suggest changes to drivers' state of mind, who in times of economic prosperity may be more inclined to adopt riskier behaviour. However, economic conditions may be linked to the distribution of the journeys made according to the reasons for the journey; thus in times of low unemployment, there is a higher percentage of workrelated journeys.

\subsubsection{The unemployed}

Measured as the number of unemployed. The effect of this variable on accidents with injured is significant, with an elasticity of $1.97 \%$. In the case of fatal accidents the variable is not significant with an elasticity of $1 \%$. The DRAG models that have included this variable in accident models (DRAG-2, TRULS, TAG and DRAGBelgium), have also obtained accident-related negative elasticities, although with lower values. This may be due to the different rates of unemployment between these countries (Quebec, Norway, France, Belgium) and Spain during the periods of application.

\subsection{Calendar variables}

The models produced reflect the influence of weekends and public holidays on accidents.

\subsubsection{Saturdays, Sundays and public holidays}

Measured as the number of Saturdays, Sundays and public holidays in the month. The models produced give an elasticity of $0.66 \%$ associated with accidents with injured and $1.71 \%$ for fatal accidents. These figures practically coincide with the increase for a Saturday, Sunday or public holiday falling in the month. The type of journey made on non-working days could explain the fact that elasticity associated with fatal accidents is higher than that for injured. The results found in other DRAG models agree with those found here, both in sign and value.

\subsection{Vehicle stock characteristics}

One of the differences in respect of other DRAG models made is the analysis of a variable directly associated with active safety like ABS. Up to now, only the DRAG-2 Quebec model had included variables of this type, without obtaining any satisfactory results, due mainly to the relatively short space of time for examining the impact of this factor. 
The effect of ABS on accidents has been mainly studied in the United States. Clear conclusions cannot be extracted from the results available on the impact on accidents as a whole, since some have focused on the analysis of specific types of collisions. Among the main works worthy of mention are those by Kahane (1994), Hertz, Hilton, and Johnson (1995 and 1998), Evans and Gerrish (1996), Evans (1998), Farmer (2001) and Delaney and Newstead (2004). In general, these studies appear to show that vehicles fitted with $A B S$, may present a higher risk of accidents without a third party, while the risk of colliding with other vehicles declines. However, Farmer (2001) has suggested that the ABS effect may have improved as drivers have gradually adapted their behaviour to the new system.

However, this work has also included a variable linked to the age of the vehicle stock. There are few models that have studied the influence of vehicle age on accidents. In the DRAG models made, only the TRULS model includes the vehicle stock average age as a vehicle characteristic-related variable, obtaining positive elasticities for accidents with victims. Fontaine (1998), using French data, reported that the accident risk (number of accidents per kilometre travelled) for cars over ten years old, is $60 \%$ higher than for cars under three years old.

\subsubsection{Proportion of vehicle stock fitted with ABS}

Measured as the percentage of vehicle stock cars fitted with ABS. The results show the effectiveness of ABS in reducing accidents, mainly fatal ones, with elasticities of $0.65 \%$ in this case, and $0.12 \%$ in accidents with injured.

\subsubsection{Proportion of vehicles over 10 years old}

Measured as the percentage of vehicle stock over ten years old. As was to be expected, the impact of this variable on accidents is negative, that is to say, as the percentage of these vehicles increases so do accidents, in a proportion of $8.71 \%$ for injured and $8.89 \%$ for fatalities. These figures are high when compared to previous studies by the research team and other authors. A possible explanation for these results may be had in the high density migrant phenomenon produced in Spain in recent years; for economic reasons a large number of the oldest vehicles are purchased by these groups whose driving habits may be different according to the country of origin; however, as these vehicles are for every use, the number of interurban journeys may be more than for other users who may possess a vehicle over 10 years old as a second family car for mainly urban use. It is therefore possible to put forward a hypothesis that correlates vehicle age and certain driver characteristics that have not been included in the models, leading to an overestimation of elasticities. However, these results should be validated by other types of analysis.

\subsection{Surveillance and sanctions}

Up to now no DRAG model has included road surveillance and control-related variables except the models for Quebec that have a "frequency of police rounds" variable. In the I-DE model, three variables directly related to this sphere were included: the number of random breath tests, the number of civil guard officers from the traffic department, and the number of driving licences suspended or withdrawn. With these variables it is intended to analyse what impact police presence and actions have on safety, the control of unsafe behaviour and the effect of sanctions.

\subsubsection{Random breath tests}

Measured through the total number of breath test checks. As with learner drivers, this variable shows a strong link between alcohol and fatal accidents with a negative elasticity of $1.38 \%$. In the case of accidents with injured, elasticity is reduced to an insignificant figure of $-0.04 \%$. This would appear to show the effectiveness of checks in reducing behaviour that has the highest risk.

\subsubsection{Number of officers in the civil Guard traffic department}

Measured through the total number of traffic officers. The Civil Guard Traffic Department is the police corps entrusted with the surveillance of Spain's interurban road network. From the model results it can be gathered that an increase in the number of traffic officers contributes considerably to a reduction in accidents. The elasticities obtained by the model ascribe a greater influence of police officers on fatal accidents, with a $-3.59 \%$ elasticity, than on accidents with injured, where the elasticity is $-2.09 \%$. These figures may be considered high, but they could perhaps be explained through two unquestionable facts: the high technical training of the officers, which leads to effective action on the road and the large extent to which their work is accepted by citizens.

\subsubsection{Number of driving licence suspensions and confiscations}

A rise in driving licence suspensions also has positive effects on road safety. In this case, the elasticities found in the model are $-0.27 \%$ for accidents with people injured and $-0.69 \%$ for fatal accidents. It is clear that this measure has a large impact on drivers regardless of their economic resources, unlike monetary sanctions.

\subsection{Speed}

Analysing the influence of a variable like speed through an econometric model is extremely complicated, due mainly to a lack of reliable data on actual circulation speeds on interurban roads as a whole. To mitigate this lack, a variable has been included, which, if it does not let the effect of speed on accidents be measured directly, does allow measuring to what extent vehicles circulating above the legal speed limits have an influence on accidents. The variable used is the percentage of drivers caught in radar checks carried out on the urban road network. Although these checks do not cover the entire interurban network (mobility framework of the model), it may be assumed that they represent a sample of vehicle behaviour throughout the network. Authors like Hook, Kirkwood, and Evans (1995), Chen, Meckle, and Wilson (2002), Mountain, Hirst, and Maher (2005), Goldenbeld and Schagen (2005), and Hirst, Mountain, and Maherb (2005) indicate a clear positive influence of radar checks on accident safety.

Of all the DRAG models only the model designed for France (TAG) includes speed as an explanatory variable, with very significant results and elasticities near to $11 \%$ in accidents with injured and $18 \%$ in fatal accidents.

\subsubsection{Percentage of vehicles reported in radar checks}

Measured as the percentage of vehicles reported as a result of circulating at a speed above the maximum permitted. The results found show the influence of this type of high risk behaviour on accidents, since as the number of vehicles reported in checks increases, the number of accidents increases. In this case the elasticity of accidents with injured is $0.9 \%$ and fatal accidents $0.96 \%$. One effect of this measurement that is not evaluated in this work is the reduction in circulation speed on drivers as a whole caused by radar checks.

\subsection{Legislative measures}

During the study period two particularly important acts came into force: the Traffic Regulations Reform Act (June-1992) and the Act to reduce the blood alcohol levels permitted (May, 1999). The June 1992 Act, was analysed by García-Ferrer, De Juan, and Poncela (2006), using structural models combining economic variables (IPI, 
Registrations, petrol or diesel consumption) with others of a legislative nature that gave results indicating a drop in accidents with victims of between $12.3 \%$ and $13.2 \%$.

\subsubsection{Act reducing the permitted limits of blood alcohol}

In May 1999, limits for blood alcohol were reduced from 0.8 to 0.5 for drivers of light vehicles and from 0.5 to 0.3 for heavy goods drivers. This act had an important effect on fatal accidents according to the results obtained by the model, with a drop of $4.4 \%$. The results for accidents with injured victims are not significant with an estimated coefficient of $+0.8 \%$.

\subsubsection{Act}

According to the models, this act reduced accidents with injured victims by $14 \%$ and fatal accidents by $12.3 \%$. Although the results are similar to those previously mentioned, it is not possible to rule out the hypothesis that the elasticities found are reflecting other factors not included in the model. 1989 saw the highest number of accidents and fatalities in the history of Spain. From that year on, social alarm began to grow very considerably as did social debate. This led to a greater presence of the issue of road safety in the mass media, an analysis of the factors of influence and possible solutions for reducing road accident rate figures to the maximum. All this caused a change of behaviour in many drivers who adhered more to existing regulations and laws, among other factors. When the law came into force, it had to contain all the elements that are difficult to include in a model like the one developed.

\section{Conclusions}

DRAG methodology has been applied to Spain in order to analyse the influence of factors such as socioeconomic, environmental, technological and legislative factors on accidents with injured victims and fatalities occurring on interurban roads.

An exhaustive study has been made of the different sources of official information in order to obtain monthly data of all the variables chosen, for the period 1990-2004 (180 observations of each variable). Considerable additional work has been conducted to adapt some data, some of originally annual and quarterly frequency, to the required monthly basis by deciding and applying the most appropriate methods to distribute the figures over the required frequency without introducing any significant alterations to the actual distribution.

Nineteen independent variables have been included in the final accident models grouped together under ten categories: exposure, infrastructure, weather, drivers, economic variables, vehicle stock characteristics, surveillance, speed and legislative measures.

The results allow highly interesting conclusions to be reached concerning the different effects of each variable on each accident type considered (with injured and fatalities). From the analysis it becomes clear that there are specific characteristics associated with the severity of accidents and the usefulness of a disaggregated study of the phenomenon. The greatest influencing factor is exposure, which together with inexperienced drivers, speed and the ageing vehicle stock, have a negative effect, while an increase in road surveillance, technological improvements to vehicles and the high capacity network, have a positive effect, leading to a drop in accidents.

The results obtained agree well with those found by other authors and with what was to be expected from a knowledge of the phenomena associated with each case.

\section{Acknowledgements}

This research with reference TRA-2004-07886/AUT was financed by the 2004-2007 National research and Development
Plan, the Government's General Traffic Directorate and the Spanish Association of Automobile and Lorry Manufacturers (ANFAC). The project is part of the SEGVAUTO project framework, of the Madrid Regional Government. The research team would like to thank Marc Gaudry for his comments and recommendations that have contributed to improving the I-DE model.

\section{References}

Andreescu, M., \& Frost, D. B. (1998). Weather and traffic accidents in Montreal, Canada. Climate Research, 9, 225-230.

Bonneson, J. A., \& McCoy, P. T. (1993). Estimation of safety at two-way stopcontrolled intersections on rural highways. Transportation Research Record, 1401 $83-89$

Blum, U., \& Gaudry, M. (1999). SNUS-2.5, a multimoment analysis of road demand, accidents and their severity in Germany, 1968-1989. Publication CRT-99-07. Centre de recherche sur les transports. Université de Montréal.

Boyce, T. E., \& Geller, E. S. (2002). An instrumented vehicle assessment of problem behavior and driving style: do younger drivers actually take more risks? Accident Analysis and Prevention, 34(1), 51-64.

Clarke, D., Ward, P., Bartle, C., \& Truman, W. (2006). Young driver accidents in the UK: the influence of age, experience and time of day. Accident Analysis and Prevention, 38(5), 871-878.

Copper, P., Pinili, M., \& Chen, W. (1995). An examination of the crash involvement rates of novice drivers aged 16 to 55. Accident Analysis and Prevention, 27(1), $89-104$.

COST 329. (1999). Models for traffic and safety development and interventions. final report of the action. Directorate General for Transport, European Commision.

Chen, G., Meckle, W., \& Wilson, J. (2002). Speed and safety effect of photo radar enforcement on a highway corridor in British Columbia. Accident Analysis and Prevention, 34(2), 129-138

Delaney, A., \& Newstead, S. (2004). The effectiveness of anti-lock brake systems a statistical analysis of Australian data. Perth, Western Australia. Proceedings 2004 road safety research, policing and education conference, 14-16 November Vol. 1 (pp. 10)

Eisenberg, D. (2004). The mixed effects of precipitation on traffic crashes. Accident Analysis and Prevention, 36(4), 637-647.

Elvik, R., \& Vaa, T. (2004). The handbook of road safety measures. Oxford: Elsevier Science Publishers.

Evans, L., \& Gerrish, P. H. (1996). Antilock brakes and risk of front and rear impact in two-vehicles crashes. Accident Analysis and Prevention, 28(3), 315-323.

Evans, L. (1998). Antilock brake systems and the risk of different types of crashes in traffic. In 6th international technical conference on the enhanced safety of vehicles.

Farmer, C. M. (2001). New evidence concerning fatal crashes of passenger vehicles before and after adding antilock breaking system. Accident Analysis and Prevention, 33, 361-369.

Fontaine, H. (1998). Changes in exposure and accident risk for car drivers in France. In 16th international technical conference on the enhanced safety of vehicles.

Fournier, F., \& Simard, R. (1999). Modèle économétrique DRAG-2: Prévisions sur le kilométrage, le nombre d'accidents et de victimes pour la période 1997-2004. Société de l'assurance automobile du Québec.

Fridstrøm, L., \& Ingebrigtsen, S. (1991). An aggregate accident model based on pooled regional time-series data. Accident Analysis and Prevention, 23(5) 363-378.

Fridstrøm, L., Ifver, J., Ingebrigtsen, S., Kulmala, R., \& Thomsen, L. K. (1995) Measuring the contribution of randomness, exposure, weather and daylight to the variation in road accidents counts. Accident Analysis and prevention, 27(1) $1-20$.

Fridstrøm, L. (1997). TRULS: an econometric model of road use, accidents and their severity. Oslo: Institute of Transport Economics, Norwegian Centre for Transport Research.

García-Ferrer, A., De Juan, A., \& Poncela, P. (2006). Forecasting traffic accidents using disaggregated data. international. Journal of Forecasting, 22(4), 203-222.

Gaudry, M. (1984). DRAG, un modèle de la Demande Routière, des Accidents et de leur Gravité, appliqué au Ouébec de 1956-1982. Publication CRT-359. Centre de recherche sur les transports, et Cahier \#8432, Département de sciences économiques. Université de Montréal.

Gaudry, M., \& Lassarre, S. (2000). Structural road accidents models: the international DRAG family. Oxford: Elsevier Science Publishers.

Graham, J. D., \& Garber, S. (1984). Evaluating the effects of automobile safety regulation. Journal of Policy Analysis and Management, 3, 206-224.

Gregersen, N., \& Bjurulf, P. (1996). Young novice drivers: Towars a model of their accident involvement. Accident Analysis and Prevention, 28(2), 229-241.

Goldenbeld, C., \& Schagen, I. (2005). The effects of speed enforcement with mobile radar on speed and accidents. An evaluation study on rural roads in the Dutch province Friesland. Accident Analysis and Prevention, 37, 1135-1144.

Hakim, S., Shefy, D., Hakkert, S., \& Hocherman, I. (1991). A critical review of macro models for road safety. Accident Analysis and Prevention, 23(5), 379-400.

Hauer, E., Terry, D., \& Griffith, M. S. (1994). Effect of resurfacing on safety of twolane rural roads in New York state. Transportation Research Record, 1467, 30-37.

Hertz, E., Hilton, J., \& Johnson, D. M. (1995). An analysis of the crash experience of passenger cars equipped with antilock braking system. Report DOT HS 808279 
Washington DC: US Department of Transportation, National Highway Traffic Safety Administration.

Hertz, E., Hilton, J., \& Johnson, D. M. (1998). Analysis of the crash experience of vehicles equipped with antilock braking systems. In An update. 16th international technical conference on the enhanced safety of vehicles.

Hirst, W. M., Mountain, L. J., \& Maherb, M. J. (2005). Are speed enforcement cameras more effective than other speed management measures? An evaluation of the relationship between speed and accident reductions. Accident Analysis and Prevention, 37, 731-741.

Hook, D. A., Kirkwood, A., \& Evans, D. (1995). Speed cameras in Oxfordshire. Highways and Transportations, 11-13.

Jaeger, L. (1998). L'évaluation du risque dans le système des transports routiers par le dèveloppement de modèle TAG. Thèse de Doctorat de Sciences Économiques, Faculté des Sciences Économiques et de Gestion. Strasbourg: Université Louis Pasteur.

Joksch, H. C. (1984). The relation between motor vehicle accident deaths and economic activity. Accident Analysis and Prevention, 16(3), 207-221.

Kahane, C. J. (1994). Preliminary evaluation of the efectiveness of antiblock brake systems for passenger cars. Report DOT HS 808 206. Washington DC: US Department of Transportation, National Highway Traffic Safety Administration.

Kulmala, R. (1995). Safety at rural three-and four arm junctions. Development and application of accident prediction models. Espoo, Finland: VTT Publications 233. The technical Research Centre of Finland.

Lassarre, S. (1994). Cadrage méthodologique d'une modélisationpour un suivi de l'insêcuritê routière. Synthèse INRETS $\mathrm{n}^{\circ} 26$, Arcueil.

Lassarre, S. (2000). Analysis of progress in road safety in ten European countries. Accident Analysis and Prevention, 33(6), 743-751.

Liem, T., Gaudry, M., Dagenais, M., \& Blum, U. (2000). Level: The L-1.5 program for BC-GAUHESEQ (Box-Cox generalized autoregressive heteroskedastic single equation) regression and multimoment analysis. In M. Gaudry, \& S. Lassarre (Eds.), Structural road accident models: the International DRAG Family (pp. 263-324). Oxford: Elsevier Science.

McCarthy, P. (1999). TRAVAL-1. A model for California. In M. Gaudry, \& Lassarre S. (Eds.), Structural Road Accidents Models: The International DRAG family. Oxford: Elsevier Science Publishers, 2000.

Mountain, L., Fawaz, B., \& Jarret, D. (1996). Accident prediction models for roads with minor junctions. Accident Analysis and Prevention, 28(6), 695-707.

Mountain, L.J., Hirst, W. M., \& Maher, M.J.(2005). Are speed enforcement cameras more effective than other speed management measures? The impact of speed management schemes on $30 \mathrm{mph}$ roads. Accident Analysis and Prevention, 37(4), 742-754.

OECD Road Transport Research. (1997). OCDE/GD (97)153. Road Safety Principles and Models: Review of Descriptive, Predictive, Risk and Accident Consequence Models, Paris: OCDE-OECD.
Page, Y. (2001). A statistical model to compare road mortality in OECD countries. Accident Analysis and Prevention, 33(3), 371-385.

Partyka, S. C. (1984). Simple models of fatality trends using employment and population data. Accident Analysis and Prevention, 16(6), 211-222.

Partyka, S. C. (1991). Simple models of fatality trends revisited seven years later. Accident Analysis and Prevention, 23(5), 423-430

Robertson, L. S. (1981). Automobile safety regulation and death reductions in the United States. American Journal of Public Health, 71(8), 818-822.

Sävenhed, H (1994). Relation between winter road maintenance and road safety. VTIsärtryck 214. Reprint from Technical Report Ixth PIARC International Road Congress, March 21-25, Seefelt, Austria. Linköping: Väg-och transportforskningsinstitutet (VTI).

Scuffham, P. A., 1998. An econometric analysis of motor vehicle traffic crashes and macroeconomic factors. Ph.D. thesis, University of Otago, Dunedin, New Zealand.

Start, M. R., Kim, J., \& Berg, W. D. (1996). Development of safety-based guidelines for treatment of pavement rutting. No 4A, Part 5, 79-98 Proceedings of the conference road safety in Europe and strategic highway research program(SHRP), Prague, the Czech Republic, September 20-22. Linköping: Swedish National Road and Transport Research Institut.

Tegnér, G. (1998). Human behaviour and road traffic safety-a regional, Swedish longterm perpective- The DRAG-Stockholm-2 Model. TRANSEK Consultants.

Tromp, J. P. M., (1994). Road safety and drain asphalt (ZOAB). Paper presented the conference road safety in Europe and strategic highway research program, 26-28 September, Preprint SHRP 28/9. Lille, France.

Van den Bossche, F., \& Wets, G. (2003). A Structural road accident model for Belgium, Limburgs Universitair Cemtrum RA-2003-21.

Wagennar, A. C. (1984). Effects of macroeconomic conditions of the incidence of motor vehicles accidents. Accident Analysis and Prevention, 16(3), 191-205.

Wong, S.-Y. (1990). Effectiveness of pavement grooving in accident reduction. ITE Journal, July, 60(7), 34-37.

Zlatoper, T. J. (1984). Regression analysis of time series data on motor vehicle deaths in the United States. Journal of Transport Economics and Policy, 18(3), 263-274.

Zlatoper, T. J. (1987). Testing for functional form and autocorrelation in the analysis of motor vehicles deaths. Quarterly review of Economics and Business, 27(4), 6-17.

Zlatoper, T. J. (1989). Models explaining motor vehicle death rates in the United States. Accident Analysis and Prevention, 21(2), 125-154.

Zlatoper, T. J. (1991). Determinants of motor vehicle deaths in the United States: a cross-sectional analysis. Accident Analysis and Prevention, 23(5), 431-436. 